Bull. Mater. Sci., Vol. 6, No. 6, December 1984, pp. 971-977. (C) Printed in India.

\title{
A novel method of RF powder sputtering
}

\author{
K SOLOMON HARSHAVARDHAN and K N KRISHNA \\ Materials Research Laboratory, Indian Institute of Science, Bangalore 560012, India \\ MS received 12 June 1984
}

\begin{abstract}
A new method of RF sputtering by which thin films of metals, semiconductors and insulators can be sputtered from their respective powders, has been successfully demonstrated. The films have been characterized for their surface and crystal structure using conventional methods of SEM and TEM. All the films are amorphous with a relatively smooth surface topography. The relative merits and demerits of the technique have been briefly discussed.
\end{abstract}

Keywords. RF sputtering; target; shield: Crookes dark space; amorphous films; scanning electron microscopy; transmission electron microscopy.

\section{Introduction}

Owing to their remarkable performance RF sputtering techniques have evolved as indispensable tools for vapour deposition of materials (Holland 1956; Chopra 1969; Jackson 1970; Maissel and Glang 1970). The technique offers manifold advantages over the other conventional methods such as thermal (resistive heating) and electron beam evaporation when a precise control over the film composition, thickness and adhesion is desired (Chopra 1969).

By definition, sputtering is the physical removal of the surface atoms of a solid target by the energetic particle bombardment and is caused by the momentum transfer of the incoming particles to the atoms near the surface layers of the solid. The ejected atoms can be deposited onto suitably placed substrates. Sputtering can be categorized into DC and RF sputtering. The former method is used effectively for sputtering of metal targets (Maissel and Glang 1970) but fails in insulating (dielectric) and semiconducting targets because of the build-up of a surface charge of positive ions on the insulator for semiconductor) which prevents any further ion bombardment (Holland 1956; Chopra 1969). Applications of an RF field, in such cases, removes the inherent problems by providing swarms of secondary electrons from the plasma, which neutralize the positive space charge.

Targets used in conventional or commercial systems are fabricated in the form of discs and are secured to the target holders which are often water cooled. The targets are generally supported or suspended horizontally, fastened to the chamber top plate and electrically insulated from it. The substrates are kept below the target on a plate at a distance of $\sim 8 \mathrm{~cm}$ and can be maintained either at ground potential or at a negative bias. Fabrication of such targets involves long and cumbersome procedures primarily because of the geometrical constraints of the existing set-up in commercial instruments. Further, the amount of material and the cost involved in making such targets can be enormous, particularly when large area targets are desired. Hence, there is a definite 
need to improve the geometrical set-up, so that the efficiency of the technique can be considerably enhanced. We have successfully solved this problem by redesigning the apparatus. The present paper reports this simple and versatile technique by which practically all types of materials can be sputtered as thin films, the material being taken in the form of compressed powders.

\section{Conventional and redesigned RF sputtering}

Block diagrams of a conventional RF sputtering system with its important accessories and the redesigned (modified) apparatus are shown in figures $1 \mathrm{a}$ and $\mathrm{b}$ respectively. The sputtering system used (Materials Research Corporation, USA, Model SEM-8622) is provided with a $13.56 \mathrm{MHz}$ RF generator capable of producing a maximum output power level of $1.5 \mathrm{~kW}$. A capacitatively coupled tuning network is used for impedance matching between the generator and the load. Before each sputtering run, the system is evacuated $\left(\sim 10^{-7}\right.$ Torr) using standard high speed oil diffusion pumps (Varian Associates, USA). Sputtering was performed in an argon plasma at a constant pressure of $2 \times 10^{-3}$ Torr. The pressure was controlled using a micrometer leak valve. High purity argon gas ( $99.999 \%$, Indian Oxygen Limited) was used. During sputtering, liquid nitrogen was circulated in the cryo-trap to reduce contamination either from the backstreaming of vapours of diffusion pump oil or from the adsorbed gases inside the chamber.

Unlike in the conventional system (figure 1a), the cathode in the modified set-up (figure $1 \mathrm{~b}$ ) is at the bottom of the chamber and the substrates are kept on the top at a distance of $\sim 8 \mathrm{~cm}$. The powdered form of the material to be sputtered is uniformly spread into a circular trough $(0.5 \mathrm{~mm}$ depth and $50 \mathrm{~mm}$ dia.) machined out from a stainless steel plate. The target and the target holder are thus integrated into one single element. The powder is first compressed into the trough using a hydraulic press at loads of $\sim 5000-10000 \mathrm{~kg}$ and the holder is then secured to the cathode which is watercooled.

The circular area surrounding the target (usually $<6 \mathrm{~mm}$ in thickness) which does not glow during the sputtering process is called the Crookes dark space (Maissel and Glang 1970; Chopra 1969). When electrons leave the target and move under the influence of an RF field, they travel some distance before picking up energy from the field and making ionizing collisions with inert gas atoms. This distance is determined by the pressure of the gas. As a result there is no ionization in this region and hence no discharge in the immediate vicinity of the target. This fact has been exploited by us for placing a shield over the cathode (figure 1b). The shield has a central aperture, the area of the aperture being determined by the area from which sputtering from the target is desired. The crucial feature of the design is that, the shield is at the ground potential and the shield to target distance is less than the Crookes dark space. Further, the annulus in the shield must follow all the contours of the cathode-target combination such that at no point the distance between them exceeds the length of the Crookes dark space, at the working pressure of the sputtering gas. The target-to-shield distance should not be made very small so as to avoid loss of power to the target. The typical distance used was $4 \mathrm{~mm}$ at a working pressure of $\sim 2 \times 10^{-3}$ Torr and the aperture diameter was $\sim 50 \mathrm{~mm}$. It may be worthwhile to note that the plasma is confined in space in the shape of a truncated cone, with its smaller end fitting into the annulus in the shield (figure $1 \mathrm{~b}$ ). Further, for a fixed area of the aperture, the cone diameter at the minimum can be made 


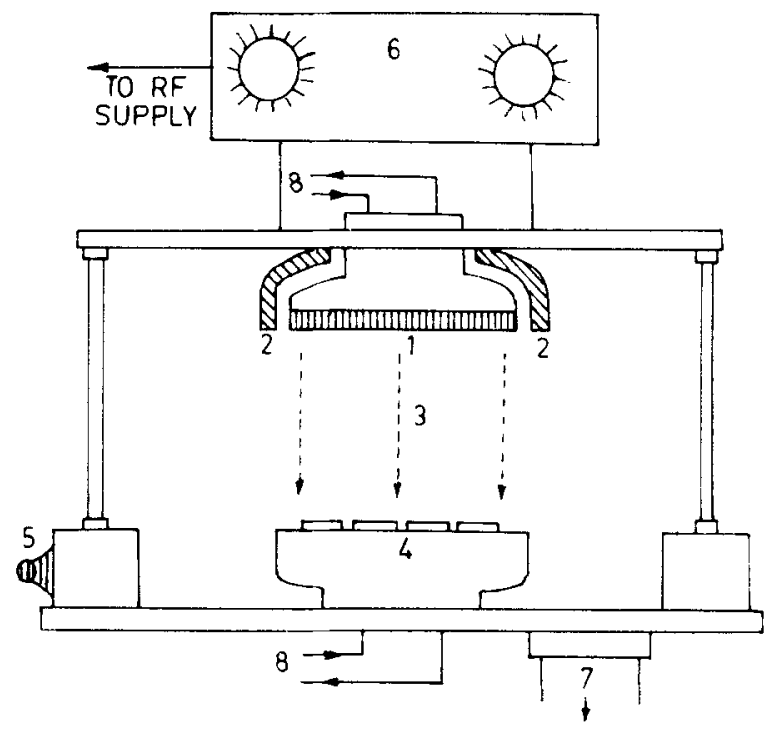

(a)

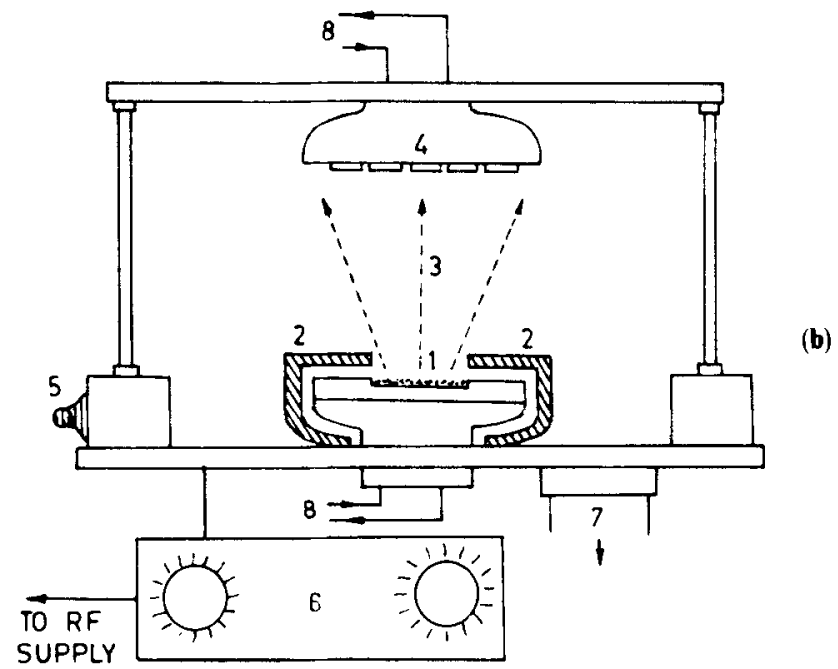

Figure 1. Block diagrams of the RF sputtering system with the important accessories a. Conventional and b. Modified. (1-target, 2-cathode shield, 3-plasma region, 4-anode (substrate holder), 5-argon gas inlet, 6-RF tuning network, 7-gasoutlet, 8-coolant water).

smaller by reducing the argon gas pressure. However, this flexibility is limited and beams approximately $20 \mathrm{~mm}$ less than the aperture diameter can be obtained.

\section{Sputtering and characterization of films}

This method which is essentially a powder sputtering method has been successfully used by us for depositing thin films of metals such as $\mathrm{Cu}$ and $\mathrm{Al}$, semiconductors such as $\mathrm{Ge}, \mathrm{Se}, \mathrm{As}_{2} \mathrm{Se}_{3}$ and insulators such as $\mathrm{SiC}$. Typical RF power levels and other sputtering parameters used are listed in table 1. 
Table 1. Deposition parameters of various materials.

\begin{tabular}{|c|c|c|c|c|c|}
\hline \multirow[b]{2}{*}{$\begin{array}{l}\text { Material } \\
\text { sputtered }\end{array}$} & \multirow[b]{2}{*}{$\begin{array}{l}\text { RF power } \\
\text { (W) }\end{array}$} & \multirow{2}{*}{$\begin{array}{l}\text { Target } \\
\text { potential } \\
\text { (V) }\end{array}$} & \multirow{2}{*}{$\begin{array}{c}\text { Sputtering } \\
\text { pressure } \\
\left(\times 10^{-3}\right) \\
(\text { Torr })\end{array}$} & \multicolumn{2}{|r|}{ Nature of the films } \\
\hline & & & & $\begin{array}{l}\text { Present } \\
\text { work }\end{array}$ & $\begin{array}{l}\text { Earlier Reports } \\
\text { (References) }\end{array}$ \\
\hline $\mathrm{Cu}$ & 200 & 1000 & 2 & Amorphous & $\begin{array}{l}\text { Polycrystalline (Buckel 1959; Patten } e t \\
\text { al 1971; Segmuller 1973) }\end{array}$ \\
\hline $\mathrm{Al}$ & 325 & 700 & 2 & Amorphous & $\begin{array}{l}\text { Polycrystalline (Barna et al 1970; Bosnel } \\
\text { and Thomas 1972; Tellier and Tosser } \\
\text { 1977; Sherman 1977) }\end{array}$ \\
\hline $\mathrm{Ge}$ & 175 & 1200 & 2 & Amorphous & $\begin{array}{l}\text { Amorphous (de Neufville 1972; } \\
\text { Kolomiets et al 1976; Tauc 1970) }\end{array}$ \\
\hline $\mathrm{Se}$ & 100 & 1200 & 2 & Amorphous & $\begin{array}{lcc}\text { Amorphous } & \text { (Grigorovici } & 1969 ; \\
\text { Kolomiets et al 1976; Lucovsky } & \text { 1967) }\end{array}$ \\
\hline $\mathrm{As}_{2} \mathrm{Se}_{3}$ & 75 & 60 & 2 & Amorphous & $\begin{array}{l}\text { Amorphous (de Neufville 1972; } \\
\text { Kolomiets et al 1976; Tauc 1970) }\end{array}$ \\
\hline $\mathrm{SiC}$ & 325 & 1800 & 10 & Amorphous & $\begin{array}{l}\text { Amorphous (Fritzsche 1973), } \\
\text { Polycrystalline (Nishino et al 1977) }\end{array}$ \\
\hline
\end{tabular}

The powder sputtered films of various materials were characterized for their surface morphology and structures. The surface morphology, surface roughness and the topology of the gross microstructure were investigated (Cambridge Stereoscan-150 SEM). Prior to the analysis, the films were coated with a thin layer of sputtered gold (when non-conducting specimens were studied), to reduce the charging and blurring effects which lead to the loss of definition and resolution of the image particularly at higher magnifications. The surface of most of the films had no distinguishing features. The SEM for a typical case of $\mathrm{As}_{2} \mathrm{Se}_{3}$ (figure 2) depicts a fairly smooth surface. Since

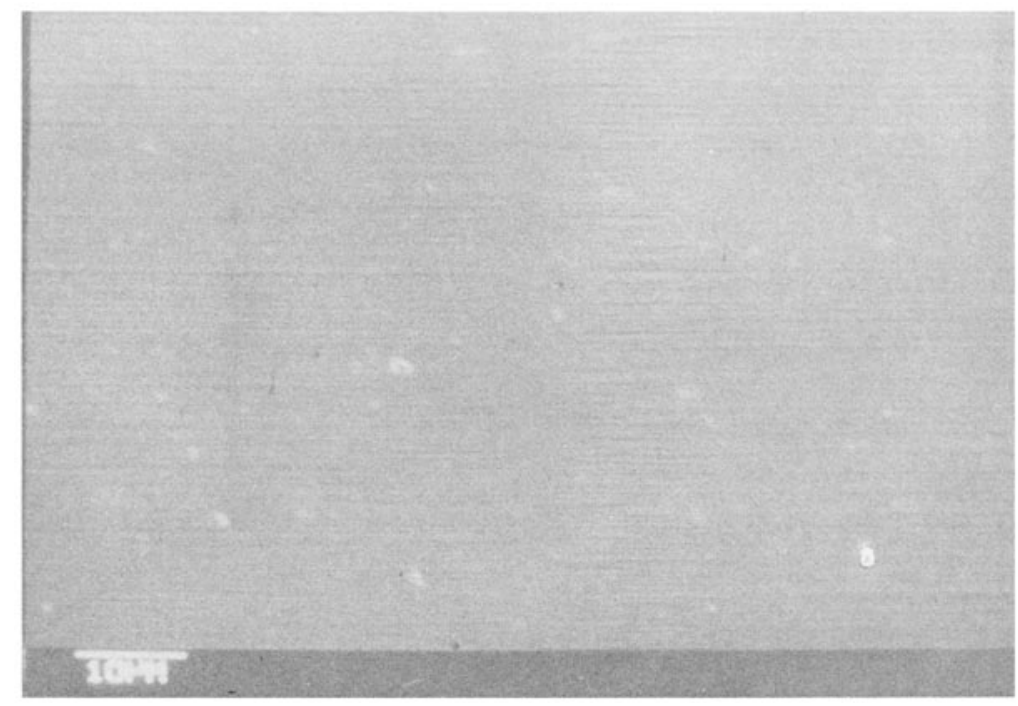

Figure 2. Scanning electron micrograph of $\mathrm{As}_{2} \mathrm{Se}_{3}$ film $(\times 1200)$.

Figure 3. Laue photographs of amorphous films of a. $\mathrm{Al}$ b. $\mathrm{Cu}$ c. $\mathrm{Ge}$ d. $\mathrm{Se} \mathrm{e.} \mathrm{As}_{2} \mathrm{Se}_{3}$ f. $\mathrm{SiC}$. 
(a)
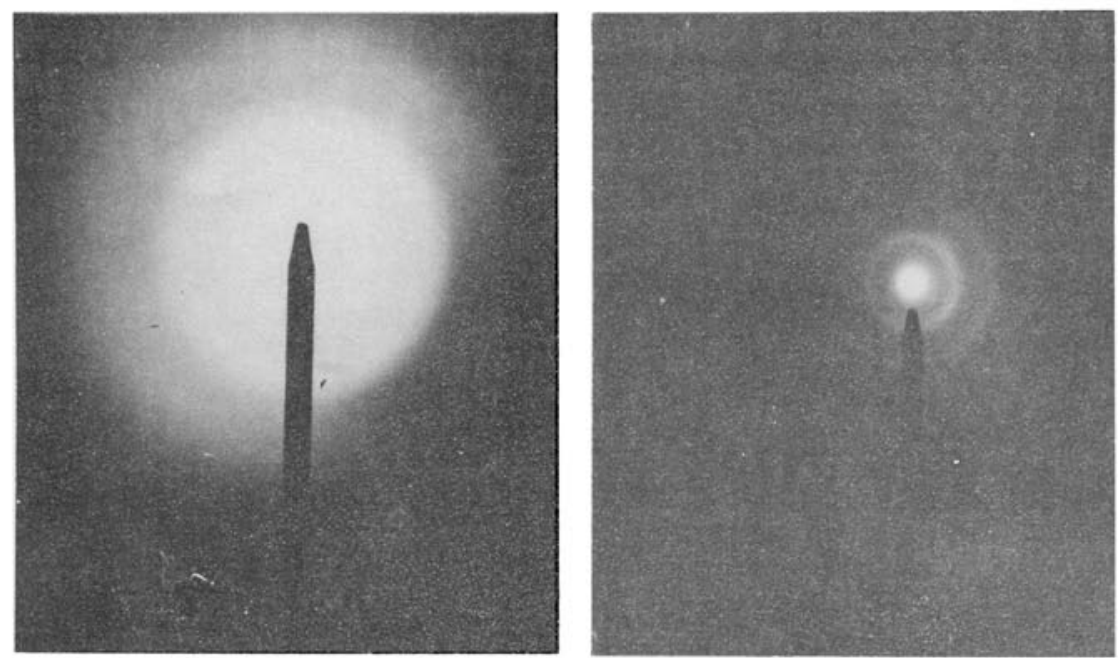

(b)

(c)
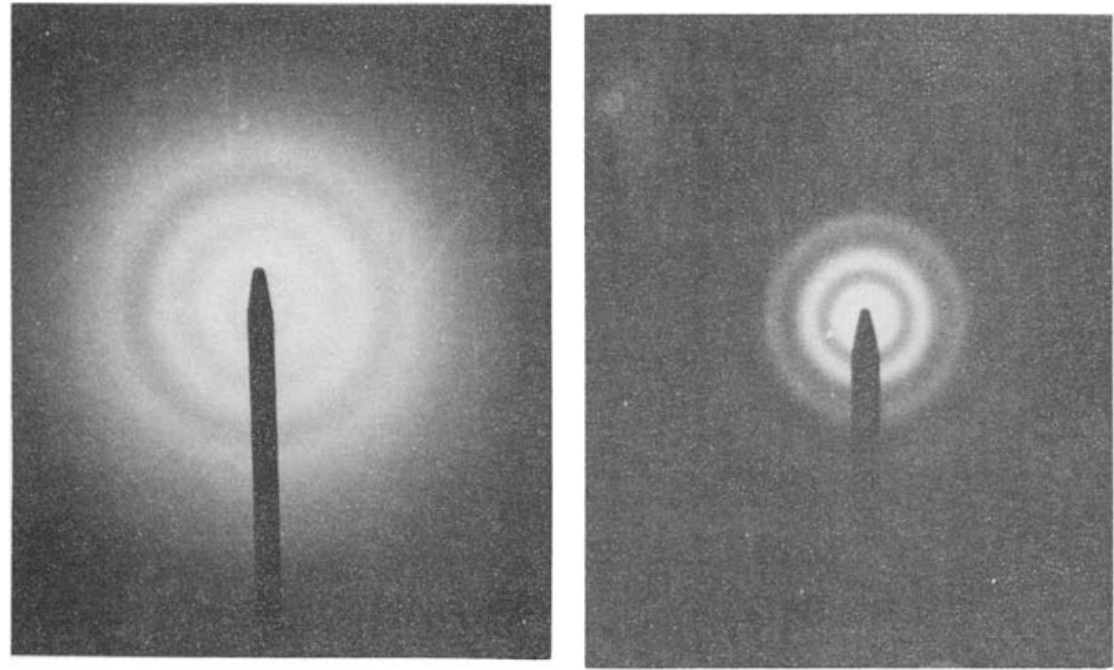

(d)

(e)
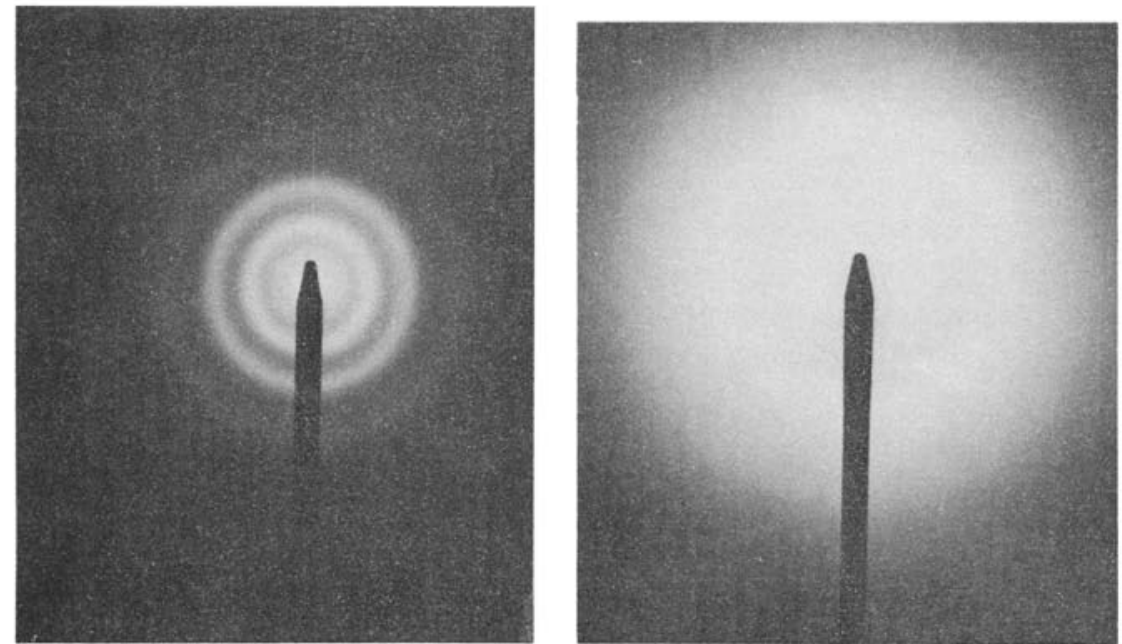

(f) 
sputtering is a high temperature deposition process, the smooth surface structure can be attributed to high adatom mobility of the sputtered species, which agrees with earlier reports (Holland 1956; Chopra 1969; Maissel and Glang 1970).

Structures of these films were investigated using electron diffraction technique. Films of thickness $500-1000 \AA$ were deposited onto freshly cleaved $\mathrm{NaCl}$ single crystals and floated in distilled water. Films were lifted onto 400 mesh copper grids. The grids were then transferred to the specimen holder of a Philips EM 301 electron microscope and examined. The diffraction patterns as well as the micrographs were recorded for all the films studied. Low beam conditions $\left(\sim 10^{-6} \mathrm{~A} / \mathrm{cm}^{2}\right)$ were used for the semiconducting films to minimize the heating effects as well as the electron beam-induced structural changes. A striking feature of all the films studied has been that their diffraction patterns were featureless halos indicating that the films were all amorphous. Though our results for semiconducting films agree with similar results (Lucovsky et al 1967; Grigorovici 1969; Tauc 1970; de Neufville 1972; Kolomiets et al 1976), there are surprising differences in the case of sputtered metal films of $\mathrm{Al}$ and $\mathrm{Cu}$, which were reported to give polycrystalline sputtered films (Buckel 1959; Patten et al 1971; Segmuller 1973; Barna et al 1970; Bosnel and Thomas 1972; Tellier and Tosser 1977; Sherman 1977) but were found to be amorphous in our studies. RF sputtered films of $\mathrm{SiC}$ have been reported to be both amorphous (Fritzsche 1973) like in the present case, and polycrystalline (Nishino et al 1977) depending on the sputtering conditions. Laue photographs of various films are shown in figures $3(a-f)$.

\section{Limitations and possible improvements of the set-up}

We have noted that the present set-up offers several advantages over the conventional sputtering methods. However, there are a few disadvantages associated with the present design. (i) By employing the cathode shield with a central aperture, the area of sputtering has been controlled but the thickness uniformity has been adversely affected. This can be minimized by a proper choice of target to substrate distance and redesigning of the substrate holder. (ii) It may be reasonably argued that undesirable gases and impurities are entrapped in the target in the present design. But such effects have not been well understood and some of these aspects are being presently investigated.

\section{Conclusions}

In the present study a simple and versatile technique for RF sputtering of thin films of metals, semiconductors and dielectrics has been described and its use has been successfully demonstrated. The method offers a cost effective means of sputtering of various materials particularly when commercial targets are not available.

\section{Acknowledgements}

The authors would like to thank Prof. C N R Rao for encouragement and Prof. K J Rao for helpful discussions. 


\section{References}

Barna A, Barna P B, Pocza J F and Pozsgai I 1970 Thin Solid Films 5201

Bosnell J and Thomas C B 1972 Solid State Electron. 151261

Buckel W 1959 Proc. Int. Conf. on Structure and Properties of thin films (eds) C A Neugebauer, J B Newkirk and D A Vermilyea (New York: John Wiley) p. 53

Chopra K L 1969 Thin Film Phenomena (New York: McGraw Hill)

de Neufville J P 1972 J. Non-Cryst. Solids 8-10 85

Fritzsche H 1973 Electronic and structural properties of amorphous semiconductors (eds) P G LeComber and J Mort (New York: Academic Press) p. 106

Grigorovici R 1969 J. Non-Cryst. Solids 1303

Holland L 1956 Vacuum deposition of thin films (Chapman and Hall) Chap. 14

Jackson G N 1970 Thin Solid Films 5209

Kolomiets B T, Lantrotova S S, Lyubin V M, Pukh V P and Tagirdzhanov M A 1976 Sov. Phys. Solid State 18 866

Lucovsky G, Mooradian A, Taylor W, Wright G B and Keezer R C 1967 Solid State Commun. 5133

Maissel L I and Glang R 1970 Handbook of thin film technology (New York: McGraw Hill) Chap. 4

Nishino S, Matsunami H, Odaka M and Tanaka T 1977 Thin Solid Films 40 L27

Patten J W, McClanahan E D and Johnston J W 1971 J. Appl. Phys. 424371

Segmuller A 1973 Thin Solid Films 18287

Sherman D 1977 Thin Solid Films 45537

Tauc J 1970 Optical properties of solids (ed) F Abeles (Amsterdam: North Holland)

Tellier C R and Tosser A J 1977 Thin Solid Films $\mathbf{4 3} 261$ 